\title{
Role of the Royal College of Physicians adviser
}

\section{A C Wicks}

\section{A personal comment}

- or the past two years I have been the - Royal College of Physicians adviser (RCA) for South Trent. This post is considered to be a very high honour and nomination and election is done by colleagues who are Fellows of the College. However, in the present environment, with so many extra commitments expected of consultant physicians, there may well be no volunteers for this role. In this situation a suitable Fellow is usually approached by the outgoing RCA, suggesting that he/she may be willing to do the job.

The candidate should be an experienced physician, although not necessarily involved in acute take. The purpose of the post is primarily to maintain the standard of general internal medicine across all medical specialties. This is becoming more important with the increasing numbers of general medical patients being admitted to all hospitals in the UK. The post has changed considerably over the last few years with greater emphasis on improved postgraduate training, and the importance of clinical governance and continuing medical education (CME) commitments. Ideally, the first two years are spent in a deputising role, sharing the duties and problems of the incumbent RCA and getting to understand the requirements of the post. The next two years are spent as RCA, and the last two years as CME adviser. There is therefore a significant commitment over a period of six years.
The RCA role is very varied and can be time consuming. In my experience approximately four to six hours a week are spent on College business. There are many local roles, which include close liaison with the College tutors and the postgraduate dean in order to improve the training standards of general internal medicine. There is a close working relationship with the Joint Committee on Higher Medical Training to ensure that there are adequate and good training programmes in general internal medicine in place as well as the specialist postgraduate programmes. A further role is assessing and evaluating the job descriptions for consultant and nonconsultant career grade posts. The assessment of a job description in a discipline other than one's own can be difficult, and it important to get advice from colleagues within the relevant field of expertise. A particularly time consuming and arduous task is collating information from colleagues and specialty advisers as to the suitability of consultants for nomination to the Fellowship of the College.

Every four years all senior house officer posts are inspected by the College and the RCA must liaise with the College tutors in the organisation of these visits. There is discussion with the College visitors about the suitability of the posts at the time of the visit. Very often, another visit is necessary after a year to evaluate again, and ensure that the proposals which were suggested have been instituted in order to provide more appropriate and better training.

There are four College meetings in London a year and these are always very interesting. The important issues of the day are discussed and future plans and ideas are raised by College officers. These meetings provide insight at first hand into government intentions on particular issues and the College's reaction to these. In addition to these meetings in London, in Trent we hold three or four meetings a year with the adjoining deaneries where common problems are discussed, and we coordinate the arrangements for postgraduate courses in the region. Some of these peripheral postgraduate meetings are sponsored by the College and a notable speaker will provide the keynote address. One of the most valuable aspects of these meetings is that the President of the College, who usually attends the College sponsored meetings, has an opportunity to speak directly to junior doctors about the problems they may be experiencing, and gets direct feedback about what is happening at the "coalface".

In summary, the RCA post is very varied, interesting, and often rewarding but is very time consuming. The consultant in this post plays a vital part in furthering the education of our young doctors, and it is essential that we have high quality postgraduate meetings to enable consultants to maintain CME. The adviser has a pivotal role between the College, the training committees, hospital trainers, the local and regional deaneries, and college tutors. I personally feel that the current demands of the post are well beyond the historic ad hoc arrangement and that it should be recognised, and paid for, as an allocated session within the holder's work programme.

Postgrad Med J 2003;79:306

Correspondence to: Dr Anthony Wicks, Leicester General Hospital, Gwendolen Road, Leicester LE5 4PW, UK; victoria.robinson@uhl-tr.nhs.uk 